\title{
Nudge Failures and Crime Indexes: Inside March-July 2018
}

\author{
Lawrence W. Sherman ${ }^{1}$
}

Published online: 19 June 2018

(C) Springer International Publishing AG, part of Springer Nature 2018

The combined first two issues of Volume 2 of the Cambridge Journal of Evidence Based Policing offer major steps forward in both falsification and innovation. The falsification of "nudge theory" under important conditions is an important step for evidence-based policing, if only because it shows the limits to external validity of any line of promising innovations. The innovation in developing a locally legitimate Crime Harm Index in two more jurisdictions is a major step in demonstrating the widespread feasibility of that approach to measuring crime.

\section{Nudging Knowledge Forward}

One common error in defining "evidence-based" policy is to claim that an innovation that works in one context will work in other contexts as well. That claim may lie more in the domain of theory-based policy, or even opinion-based policy, than in evidence-based policy. But the extent to which any test result is replicable is solely a question of evidence, at least initially. What that means for what is often called "nudge theory" is illustrated by two studies in this combined issue: even if collecting fines for court sanctions works better with text messaging than without (in a previous randomized controlled trial), that does not mean that text messages will work magic for all kinds of court processes.

In one nudge experiment, the randomized trial by Chivers and Barnes found that sending text messages to defendants the day before they were due in court had no impact on the defendants' court appearances. The reason for this failure had nothing to do with behavioural economics, and everything to with implementation. So many phone numbers were wrong in this Hampshire Police test that the defendants in the treatment group simply were not getting the text messages. Why detectives do not have correct phone numbers for

Lawrence W. Sherman

Lawrence.Sherman@crim.cam.ac.uk

1 Institute of Criminology, Cambridge University, Cambridge, UK 
these defendants, and how that might be remedied, are issues that the thoughtful article in this issue by Chivers and Barnes explores.

In the second nudge experiment, Cumberbatch and Barnes carefully demonstrate success in delivering text message reminders to victims and witnesses of an upcoming court date as a successful implementation and test of the nudge theory. The theory just failed the test. With a sample size large enough to detect even small differences, the addition of text messages to previously posted letters did not move the dial on court non-appearance rates of about one in four victims and witnesses. This finding shows that court non-appearance may require more complex solutions than text messages alone. Or it may show that different kinds of communities than those around Staffordshire might respond differently Only further testing can show which is correct. For the time being, with no difference in result but a lower cost of text messages, the local police are exploring whether to switch from posted letters to text messages for a cheaper way to get the same result.

\section{Measuring Total Crime Harm}

Both Denmark and Western Australia have been hotbeds of policing innovation in recent years. Both of their police agencies have been well-represented in the Cambridge Police Executive Programme, where many participants now measure the success of innovations on total crime harm - rather than assuming that all crime types are created equal. How and why Andersen and Mueller-Johnson do that for Denmark is fascinating, since theirs is the first Crime Harm Index to rely on prosecutorial guidelines to find consistent relative weightings for different crime categories.

In Western Australia, House and Barnes were able to take an advanced approach to using actual sentences to measure crime harm. That approach is one that limits the analysis to first offenders. Unlike the crime severity indexes of Canada, New Zealand and the UK Office of National Statistics, the Western Australian Crime Harm Index (WACHI) that they compute is restricted to data on first offenders. This method removes the influence of prior offending of the offender on each sentence, which distorts the conceptual target of measuring "harm". For a murder victim to be murdered, it matters little whether the murderer is a first offender or has many prior convictions. A measure that omits offender-oriented factors in gauging public safety is one that better calibrates victim-impact levels of harm. In offering this method for the first time, the WACHI stands with the centrality of victim harm in combating crime, which moves the spotlight away from the punishment-for-its-own sake perspective.

\section{Next Steps}

While the articles in this combined issue maintains a focus on "pracademic" research done by police professionals under academic guidance at the Cambridge Police Executive Programme, future issues this year will prove that this Journal has an open-door policy to authors not affiliated with Cambridge in any way. Even as the Cambridge Master's in Applied Criminology and Police Management community grows its global reach with many new students from Hong Kong and Denmark, we 
seek to reach thousands of other pracademics who cannot spend the time at Cambridge. Future issues this year will include the work of some in that category. We welcome other readers to join them.

Lawrence W. Sherman

Cambridge, England, June 2018

Lawrence W. Sherman Wolfson Professor of Criminology Emeritus, University of Cambridge; Distinguished University Professor, University of Maryland; Director, Cambridge Centre for Evidence-Based Policing and Editor-in-Chief, Cambridge Journal of Evidence-Based Policing. 